\title{
Indicadores de qualidade de vida dos agricultores familiares da comunidade Vale do Sol II, em Tangará da Serra, Mato Grosso
}

\section{Indicators of life quality of the family farmers from Vale do Sol II community, in Tangará da Serra, Mato Grosso}

Andréia Rezende da C. Nascimento - Mestre em Ambiente e Sistemas de Produção Agrícola, pela Universidade do Estado de Mato Grosso (UNEMAT). Professora no Instituto Federal de Mato Grosso (IFMT). E-mail: andreia.nascimento@jna.ifmt.edu.br

Jussara Giaretta - Mestre em Ambiente e Sistemas de Produção Agrícola da Universidade do Estado de Mato Grosso (UNEMAT). Professora na Universidade de Cuiabá (Unic). E-mail: jussaragiaretta@yahoo.com.br

Poliana Roma Greve Nodari - Mestre em Ambiente e Sistemas de Produção Agrícola da Universidade do Estado de Mato Grosso (UNEMAT). Professora na mesma instituição de ensino. E-mail: polianaroma@unemat.br

Cleci Grzebieluckeas - Doutora em Engenharia da Produção, pela Universidade Federal de Santa Catarina (UFSC). Professora adjunta da Universidade do Estado de Mato Grosso (UNEMAT). E-mail: cleci@unemat.br

Santino Seabra Junior - Doutor em Agronomia (Horticultura), pela Universidade Estadual Paulista Júlio de Mesquita Filho (UNESP). Professor adjunto da Universidade do Estado de Mato Grosso (UNEMAT). E-mail: santinoseabra@hotmail.com

\section{Resumo}

O estudo identificou indicadores de qualidade de vida e sua relação entre saúde, produção de alimentos e conservação ambiental na comunidade Vale do Sol II, em Tangará da Serra/MT. Trata-se de uma pesquisa descritiva, com abordagem qualiquantitativa e que teve como instrumento de coleta a aplicação de formulário semiestruturado, contendo perguntas de cunho ambiental, socioeconômico, produção de alimentos e qualidade de vida. A amostra foi composta por 40 agricultores (as) familiares. Identificou-se que todos os agricultores usam agroquímicos, porém 57,5\% utilizam Equipamentos de Proteção Individual. A principal renda das famílias é oriunda da venda de mandioca, frango e abacaxi, entretanto, pretendem diversificar com novas espécies de frutas e hortaliças. Os pesquisados definiram qualidade vida como saúde, educação, condições habitacionais, alimentação diversificada e saneamento básico, contudo, declararam que faltam ações de melhorias, tais como recursos econômicos, assistência técnica, transporte coletivo para a cidade, cursos de aperfeiçoamento na comunidade, integração social e lazer.

\section{Keywords}

Comunidade rural. Agricultura familiar. Produção de alimentos. Qualidade de vida.

\begin{abstract}
The study identified indicators of quality of life and the relationship between health, food production and environmental conservation in Sun Valley II community in Tangará da Serra MT. It is a descriptive research with qualitative and quantitative approach and was to form semistructured data collection instrument containing environment related questions, socioeconomic, food production and quality of life. The sample consisted of 40 farmers (the) interviewed family. It was identified that all farmers use pesticides but $57.5 \%$ use individual protection equipment. The main family income comes from the sale of manioc, chicken and pineapple, however, intend to diversify into new species of fruits and vegetables. Respondents defined quality of life as health, education, housing conditions, diversified supply and sanitation, however, declared missing improvement actions, such as financial resources, technical assistance, public transportation to the city, master classes in the community, social integration and recreation.
\end{abstract}

\section{Palavras-chave}

Rural community. Family farming. Food production. Life quality. 


\section{INTRODUÇÃO}

A qualidade de vida vem sendo discutida e estudada nas mais diversas áreas das ciências. No entanto, definir qualidade de vida não é tarefa fácil e o único consenso é que se trata de um conceito em construção (BARROZO et al., 2010). Esta é entendida como as condições de vida humana existentes num determinado contexto ambiental e temporal, refere-se a um estado duradouro de condições humanas, fruto do trabalho. O efeito transformador do trabalho requer determinadas condições mentais, morais, habilidades psicomotoras e vitais (TREVISAN, 2000).

A qualidade de vida aparece recorrentemente vinculada a indicadores objetivos que se referem à situação econômica e ao acesso a serviços de saúde, transporte, educação, lazer, condições habitacionais. No entanto, deve ser avaliada dentro de cada cultura específica, além de considerar sua subjetividade para locais e grupos determinados (AZEVEDO, 2008). Esse conceito é corroborado com o Relatório Final da Oitava Conferência Nacional de Saúde, o qual esclarece que saúde é resultante das condições de alimentação, habitação, educação, renda, meio ambiente, trabalho, transporte, emprego, lazer, liberdade, acesso a posse da terra e acesso a serviço de saúde (BRASIL, 1986).

As condições de qualidade de vida descritas anteriormente podem ser analisadas no contexto rural, que apesar do intenso processo de industrialização, promovido pelas políticas públicas e da acelerada migração do homem do campo para a cidade, acompanhou o processo e a produção agrícola. Contudo, as atividades rurais continuam exercendo papel importante nos cenários socioeconômico e ambiental (SIQUEIRA, 2011), aumentando a diversidade de alimentos, incrementando a produção agropecuária, elevando a renda, melhorando a qualidade de vida dos trabalhadores rurais, bem como contribuindo com a geração de emprego e redução do êxodo rural (SOUZA-ESQUERDO et al., 2013).

Apesar da sua importância, a população rural vem diminuindo ao longo dos anos, pois estudos realizados pelo Instituto Brasileiro de Geografia e Estatística (IBGE, 2010), mostraram que em 1980, 67,7\% da população nacional era urbana, enquanto 32,3\% morava no campo. Em Mato Grosso, no mesmo período, a população urbana era de 57,5\% contra 42,5\% rural e Tangará da Serra apresentava uma população urbana e rural de 40,7\% e 59,3\%, respectivamente. Em 2010, esses percentuais mudaram significativamente, sendo que em nível 
nacional havia uma população urbana e rural de 84,3\% e 15,7\%, respectivamente. Já em Mato Grosso, 81,8\% urbana e 18,2\% rural e o mesmo cenário pode ser visto em Tangará da Serra, onde 91\% urbana contra 9\% para população rural.

Diante do exposto, verifica-se que a população rural em 30 anos diminui $51,40 \%$ na escala nacional, $57,18 \%$ no estado de Mato Grosso e alarmantemente 93,55\% em Tangará da Serra. Sendo assim, surgem às indagações a respeito dos fatores que estão impulsionando o êxodo rural. Será que a produção agrícola na pequena propriedade se tornou inviável? Quais as políticas públicas que proporcionam melhorias para o homem do campo? Essas políticas são de fácil acesso a todos os agricultores?

Dessa forma, torna-se imprescindível desenvolver estudos que mostrem os gargalos no tocante à qualidade de vida na agricultura familiar e apontem indicadores que mostrem as necessidades destas famílias, visando à permanência das famílias no campo, direcionando a criação e o aperfeiçoamento de políticas públicas para a agricultura familiar. Sendo assim, o objetivo do estudo foi identificar indicadores de qualidade de vida e sua relação entre saúde, produção de alimentos, conservação ambiental na agricultura familiar da comunidade Vale do Sol II, em Tangará da Serra/MT.

\section{REFERENCIAL TEÓRICO}

\subsection{QUALIDADE DE VIDA}

O termo qualidade de vida foi empregado pela primeira vez em 1920, por Pigou (1920), sobre economia e bem-estar. Pigou (1920) discutiu o suporte governamental para pessoas de classes sociais menos favorecidas e o impacto sobre suas vidas e o orçamento do Estado. Porém, após a Segunda Guerra Mundial (1945), foi intensificado, associando o sucesso e melhoria do padrão de vida, principalmente relacionado com a obtenção de bens materiais. $O$ termo qualidade de vida voltou a ser discutido em 1964 por Lyndon Johnson, presidente dos Estados Unidos, que afirmava que os objetivos não podem ser medidos através dos balanços dos bancos, mas, através da qualidade de vida que proporcionam às pessoas (ROBLE, 2012).

A partir da visão de Lyndon Johnson, a noção de qualidade de vida tornase mais complexa e compartilhada por cientistas sociais, filósofos e políticos. A 
noção sai da esfera econômica e se expande para outras áreas do conhecimento, ligada a elementos subjetivos como a saúde e o bem-estar. Desta forma, os esforços que buscavam medir ou quantificar qualidade de vida aproximaram as ciências humanas e biológicas (AZEVEDO, 2008). Nos países da América Latina a má distribuição de renda, o analfabetismo, e o baixo grau de escolaridade, bem como as condições precárias de habitação e a degradação ambiental são fatores que interferem significativamente nas condições de vida e saúde da população (BUSS, 2000).

O estudo de Castro e Fracolli (2013) identificou que a avaliação precoce de problemas de saúde torna-se importante instrumento de prevenção e cuidado, uma vez que a avaliação em saúde pode modificar uma situação, pois diagnostica uma realidade a fim de nela intervir. Dessa forma, a avaliação da Qualidade de Vida pode ajudar a dimensionar e analisar as ações de Promoção da Saúde em curso e que poderiam ser implantadas nas comunidades e nos programas de saúde. No entanto, para que ocorra a avaliação precoce citada por Castro e Fracolli (2013), é necessário que haja políticas públicas, gestão social integrada, intersetorialidade e estratégias pontuais dos municípios para o desenvolvimento de ações que gerem bem-estar e qualidade de vida (BUSS, 2000).

\subsection{AGRICULTURA FAMILIAR}

A agricultura familiar é definida como a forma de produção onde predomina a interação entre gestão e trabalho, isto é, são os agricultores familiares que dirigem o processo produtivo, dando ênfase na diversificação e utilizando o trabalho familiar, eventualmente complementado pelo trabalho assalariado (BRASIL, 2014). A propriedade não deve ter área maior que 4 (quatro) módulos fiscais; utilizar predominantemente mão de obra da própria família nas atividades econômicas da propriedade; e possuir a maior parte da renda familiar originária do próprio estabelecimento rural (BRASIL, 2006).

O Ministério de Desenvolvimento Agrário (MDA) define agricultura familiar como a forma de produção onde predomina a interação entre gestão e trabalho, isto é, são os agricultores familiares que dirigem o processo produtivo, dando ênfase na diversificação e utilizando o trabalho familiar, eventualmente complementado pelo trabalho assalariado (BRASIL, 2014). Para ser caracterizada como agricultura familiar, alguns preceitos devem ser 
observados, a saber: possuir propriedade rural até 4 módulos fiscais; utilizar predominantemente mão de obra da própria família nas atividades econômicas da propriedade; e possuir a maior parte da renda familiar originária do próprio estabelecimento rural (BRASIL, 2006).

Nos Estados Unidos define-se agricultura familiar como aquela em que o agricultor familiar pode ser dono de pequenas ou grandes áreas, e ter propriedades que garantam pouca renda ou retorno milionário (HEBERLÊE, 2014).

Na concepção de Guanziroli (1996), a agricultura familiar possui três características centrais: a) a gestão da unidade produtiva e os investimentos nela realizados é feita por indivíduos que mantêm entre si laços de sangue ou de casamento; b) a maior parte do trabalho é igualmente exercida pelos membros da família com plenas condições de trabalho; e c) a propriedade dos meios de produção (embora nem sempre da terra) pertence à família e é em seu interior que se realiza sua transmissão em caso de falecimento ou de aposentadoria dos responsáveis pela unidade produtiva.

No Brasil a agricultura familiar ganhou notoriedade a partir da década de 1990 com o surgimento do Programa Nacional de Fortalecimento da Agricultura Familiar (PRONAF), em resposta aos anseios da associação dos trabalhadores rurais (GOUVEIA, 2010). Outros fatores também foram preponderantes: o reestabelecimento da força política, o forte movimento sindical dos trabalhadores rurais durante a década de 1990 e a criação da Lei da Agricultura Familiar (SANGALLI; SCHLINDWEIN, 2013).

No Censo Agropecuário 2006, foram identificados 4.367 .902 estabelecimentos da agricultura familiar, o que representa $84,4 \%$ dos estabelecimentos brasileiros. Dos 80,25 milhões de hectares da agricultura familiar, $45 \%$ eram destinados a pastagens, $28 \%$ às matas, florestas ou sistemas agroflorestais, e, por fim, as lavouras, que ocupavam 27\%. A área média dos estabelecimentos familiares era de 18,37 hectares (IBGE, 2006).

Apesar do pouco espaço territorial, a agricultura familiar no Brasil é responsável por garantir boa parte da segurança alimentar do País, sendo importante fornecedora de alimentos para o mercado interno (IBGE, 2006), responde por cerca de $40 \%$ da produção agrícola (COMPANHIA NACIONAL DE ABASTECIMENTO, 2013). O bom desempenho da produção agrícola familiar pode estar atrelado à oferta do crédito rural, pois, de acordo com dados extraídos do MDA (2014), evidencia-se que o crédito da agricultura familiar em 
2003/2004 era em torno de 2,3 bilhões, saltando para 21 bilhões em 2013/2014. O objetivo da ampliação do crédito rural foi aumentar a produção de alimentos, garantir mais renda no campo e melhorar a estabilidade de preço ao consumidor (MINISTÉRIO DO DESENVOLVIMENTO AGRÁRIO, 2014).

O estado do Mato Grosso possui 86.167 estabelecimentos da agricultura familiar com área de 4.884.212 hectares. Em relação às terras familiares, 65.293 estabelecimentos são próprios, 871 arrendatários, 254 parceiros, 3.710 ocupantes e 959 estabelecimentos de produtores sem área. Dos alimentos cultivados pela agricultura familiar destaca-se a mandioca, o arroz, o feijão, o milho em grão, a soja e o trigo; e, na pecuária, a criação de bovinos, aves e suínos (MINISTÉRIO DO DESENVOLVIMENTO AGRÁRIO, 2015).

A Secretaria de Agricultura familiar e Regulação Fundiária do Estado de Mato Grosso, por meio do Contrato de Gestão, documento que foi assinado em janeiro de 2015 pelo Governador do Estado e o Secretário da Agricultura, traçaram algumas metas, quais sejam: desenvolvimento sustentável, pesquisa, regularização fundiária, gestão e fortalecimento da Central de Abastecimento do Estado (Ceasa) (SOCIEDADE NACIONAL DA AGRICULTURA, 2015). O objetivo com essas medidas é o trato exclusivo à agricultura familiar (SOCIEDADE NACIONAL DA AGRICULTURA, 2015), setor que carece de atenção em todas as esferas: federal, estadual e local.

\subsection{POLÍTICAS PÚBLICAS NA AGRICULTURA FAMILIAR}

O termo política pública decorre da ciência política, que nasce nos Estados Unidos como disciplina acadêmica, porém não existe uma única definição sobre o que realmente é política pública. De acordo com Souza (2006), política pública pode ser definida como:

Um campo dentro do estudo da política que analisa o governo à luz de grandes questões públicas (MEAD, 1995); segundo Lynn (1980), é um conjunto de ações do governo que irão produzir efeitos específicos; Peters (1986), é a soma das atividades dos governos, que agem diretamente ou através de delegação, e que influenciam a vida dos cidadãos; Dye (1984) a política pública é o que o governo escolhe fazer ou não fazer. A definição de política pública mais conhecida é a de Laswell, que implica responder às seguintes questões: quem ganha o quê, por quê e que diferença faz (SOUZA, 2006 p. 24). 
Pode-se, então, resumir política pública como o campo do conhecimento que busca, ao mesmo tempo, colocar o governo em ação e analisá-la, e quando necessário propor mudanças que beneficiam a coletividade. A formulação de políticas públicas constitui-se no estágio em que os governos democráticos traduzem seus propósitos e plataformas eleitorais em programas e ações que produzirão resultados ou mudanças no mundo real que refletem na economia e na sociedade (SOUZA, 2006).

Sendo assim foi criado em 1996, a primeira política pública diferenciada voltada aos agricultores familiares, o Programa Nacional de Fortalecimento da Agricultura Familiar (PRONAF), que representa o reconhecimento, pelo Estado, de uma nova categoria social - os agricultores familiares que até então eram marginalizados em termos de acesso aos benefícios da política agrícola (DENARDI, 2001). O PRONAF tem como eixos básicos: o financiamento da produção agrícola por intermédio da concessão de financiamento da produção; o financiamento de infraestrutura e serviços municipais; a capacitação e profissionalização dos agricultores familiares (SILVA, 2000).

O Ministério do Desenvolvimento Agrário (MDA), por meio da Secretaria de Reordenamento Agrário, desenvolveu em 2003 o Programa Nacional de Crédito Fundiário (PNCF), que oferece recursos financeiros aos trabalhadores rurais, sem terra ou com pouca terra, para comprar um imóvel rural por meio de um financiamento. Os recursos são destinados à infraestrutura necessária para a produção, assistência técnica e extensão rural; o agricultor pode construir a casa, preparar o solo, comprar implementos; terá acompanhamento técnico e o que mais for necessário para se desenvolver de forma independente e autônoma (MINISTÉRIO DO DESENVOLVIMENTO AGRÁRIO, 2015).

Podem participar do PNCF trabalhadores e trabalhadoras rurais, filhos de agricultores familiares ou estudantes de escolas agrotécnicas. Os beneficiários devem ter renda familiar anual de até $R \$ 15$ mil e patrimônio de até $R \$ 30$ mil. Devem ainda comprovar mais de cinco anos de experiência rural nos últimos 15 anos. Para aderir ao PNCF o agricultor não pode ser funcionário público, nem ter sido assentado ou ter participado de algum programa que tenha recursos do Fundo de Terras da Reforma Agrária. O agricultor que adquiriu o imóvel rural maior que 4 módulos fiscais nos últimos três anos, ou tenha direito de ação e herança em imóvel rural, também não pode ser atendido pelo PNCF (MINISTÉRIO DO DESENVOLVIMENTO AGRÁRIO, 2015). 


\section{MATERIAL E MÉTODOS}

\subsection{TIPO DE PESQUISA}

A pesquisa é descritiva com abordagem qualiquantitativa. As pesquisas descritivas expõem características de determinada população ou fenômeno, podendo também estabelecer correlações entre as variáveis, definindo sua natureza, servindo como base para explicar os fenômenos que descreve (VERGARA, 2007). Objetivam também levantar opiniões, atitudes e crenças de uma população envolvendo o uso de técnicas padronizadas de coleta de dados, questionário e observação sistemática, assumindo forma de levantamento (GIL, 2007).

As pesquisas qualitativas no campo das ciências sociais respondem a questões muito particulares e se preocupam com o significado que as pessoas dão às coisas e à sua vida. Trata-se também da realidade que não pode ser quantificada. Com isso, trabalha com um universo de significados, motivos, aspirações, valores e atitudes, que corresponde a um espaço profundo dos processos e fenômenos que não podem ser reduzidos e operacionalizados em variáveis por meio de métodos e dados estatísticos, sendo uma de suas principais características o fato de trabalhar com dados descritivos (MINAYO, 2004; MATHEUS; FUSTINONI, 2006).

A pesquisa quantitativa é apropriada para medir tanto opiniões, atitudes e preferências como comportamentos. Se o interesse for saber quantas pessoas usam um produto ou serviço, ou têm interesse em um novo conceito de produto, a pesquisa quantitativa é o indicado. Ela também é usada para medir um mercado, estimar o potencial ou volume de um negócio e para medir o tamanho e a importância de segmentos de mercado (MARCONI; LAKATOS, 2007).

\section{2 ÁREA DE ESTUDO E AMOSTRA}

O estudo foi realizado no município de Tangará da Serra (Figura 1), localizado na região médio norte do estado de Mato Grosso, em área ecotonal ou de transição ecológica entre o bioma cerrado e a floresta amazônica, a $240 \mathrm{~km}$ da capital Cuiabá. Sua extensão territorial é de 11.323,681 km², população estimada em 2014 de 92.298 habitantes (IBGE, 2010). O Índice de Desenvolvimento Humano Municipal (IDHM) é de 0,729, segundo o Programa das Nações Unidas para o Desenvolvimento (2010). 
Figura 1 - Localização da área de estudo

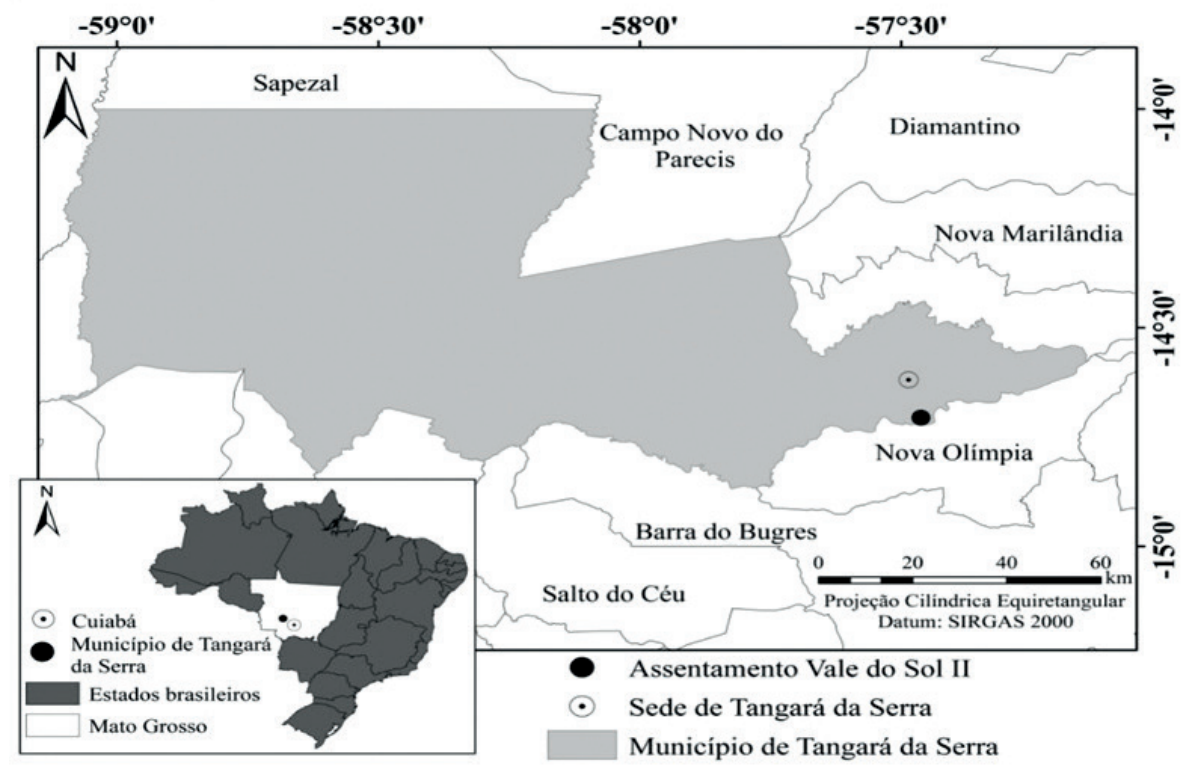

Elaboração: os autores, 2018.

A amostra foi não probabilística com base na conveniência do pesquisador (MALHOTRA, 2012), composta por 40 famílias de um total de 191 lotes na Comunidade Vale do Sol II, localizada a $19 \mathrm{~km}$ da cidade de Tangará da Serra/ MT. A comunidade foi criada em 2007, por meio do Programa Nacional de Crédito Fundiário (PNCF), sendo que cada lote possui 4 hectares.

Os instrumentos de coleta de dados foram formulários contendo perguntas abertas, que indagaram sobre qualidade de vida, relativa à educação, saúde, habitação, aspectos sanitários, lazer e bens duráveis. Por se tratar de questões abertas, surgiu mais de uma opção para cada resposta, assim, as respostas foram analisadas e condensadas conforme apresentavam e posteriormente, registradas em tabelas. O formulário foi embasado no estudo de Sousa, Khan e Passos (2002).

Os agricultores foram informados sobre a pesquisa e assinaram o Termo de Consentimento Livre e Esclarecido (TCLE) em duas vias. Esse documento assegurou aos entrevistados a possibilidade de não participar do estudo, a possibilidade de desistência em responder o formulário a qualquer momento ou pular questões que não considerassem convenientes responder. Garantiu também o anonimato daqueles que concordassem em participar da pesquisa. 
As coletas de dados foram realizadas no período de março a abril de 2015. Os critérios de inclusão foram: ter disponibilidade de responder às perguntas, ter idade igual ou superior a 18 anos, residir na comunidade e ter aderido ao Termo de Consentimento Livre e Esclarecido (TCLE). Quanto aos critérios de exclusão, foram: idade inferior a 18 anos e não ter aderido ao TCLE.

As respostas foram tabuladas e analisadas através do programa Microsoft Office Excel, utilizando recursos de imagens e tabelas.

\section{RESULTADOS E DISCUSSÕES}

\subsection{CARACTERIZAÇÃO DA COMUNIDADE, FAIXA ETÁRIA E ORIGEM DOS ENTREVISTADOS}

Os moradores da Comunidade Vale do Sol II são produtores rurais característicos da agricultura familiar que produzem alimentos para a subsistência e comercializam o excedente. $O$ trabalho realizado pelos agricultores familiares é basicamente manual, ou seja, braçal. Poucos possuem trator próprio, roçadeira de trator e roçadeira elétrica. A maioria usufrui de tecnologias básicas que exigem maior esforço físico como: enxada, foice, enxadão, bomba costal, arado de animal e outros. No entanto foi citado pelos moradores que a comunidade dispõe de um trator que presta serviço a quem reivindicar, sendo necessário arcar com as horas do tratorista.

Quando questionados sobre o tempo de residência no estado de Mato Grosso, a média de anos entre os moradores foi de 29,67, oscilando entre 7 a 50 anos. Quanto ao tempo na Comunidade Vale do Sol II, a média em anos foi de 4,46, exceto um morador que afirmou residir a mais de 15 anos, desde quando as terras pertenciam à fazenda.

Verificou-se que a faixa etária dos moradores da comunidade Vale do Sol II está entre 20 a 69 anos, sendo que a maioria (35\%) possui entre 50 a 59 de idade, 25\% entre 40 a 49 anos e 20\% entre 60 a 69 anos de idade. Observa-se, portanto, que o acesso à terra só foi possível quando $80 \%$ da população estudada estava acima de 40 anos, quando a força de trabalho começa a diminuir. Baseando-se na pesquisa, pode-se dizer que os filhos dos produtores, quando estes tiveram acesso à terra, já não moravam mais com seus pais, constituindo seus próprios núcleos familiares. Dados semelhantes sobre a faixa etária foram encontrados no 
estudo realizado por Oliveira et. al. (2013) em assentados da região Cáceres / MT, onde $78,3 \%$ dos entrevistados tinham idade entre 41 a 60 anos.

Os agricultores que residem no Vale do Sol II são migrantes de várias regiões do Brasil, distribuídos entre dez estados brasileiros (Figura 2), destacandose os estados do Paraná com 25\%, São Paulo 17,5\% e Mato Grosso com 15\%, e os demais com menor representatividade. Estes dados revelam que na comunidade ocorre grande mistura de raças e culturas.

Figura 2 - Estado de origem dos agricultores familiares residentes na comunidade Vale do Sol II, em Tangará da Serra/MT

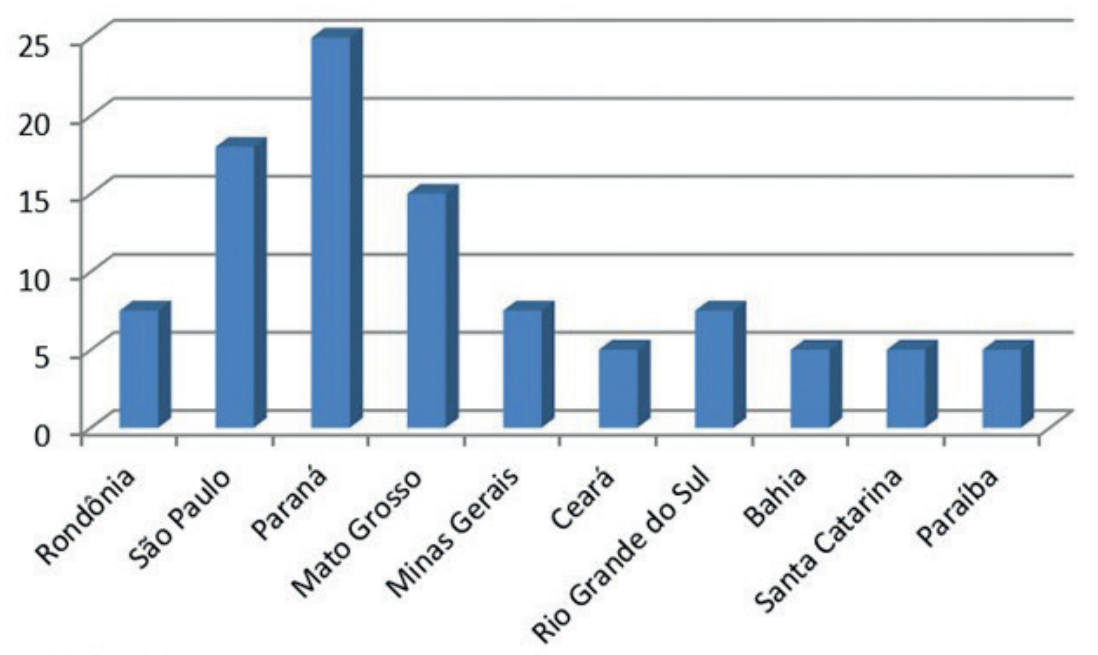

Fonte: Dados da pesquisa.

\subsection{ASPECTOS HABITACIONAIS, DE SAÚdE, HIGIENE E MEIO AMBIENTE}

Os lotes foram adquiridos em 2007, por meio do PNCF, via Banco do Brasil. O projeto contemplava uma casa de alvenaria de 42 metros quadrados, conforme exemplo na Figura 3. Desse modo, 95\% das casas são de alvenaria e somente 5\% de madeira. Algumas dessas casas foram ampliadas de acordo com a necessidade e condições financeiras de cada proprietário. Todas contam com rede de energia elétrica, fator este que pode contribuir com melhores condições de vida. 
Figura 3 - Moradia na Comunidade Vale do Sol II

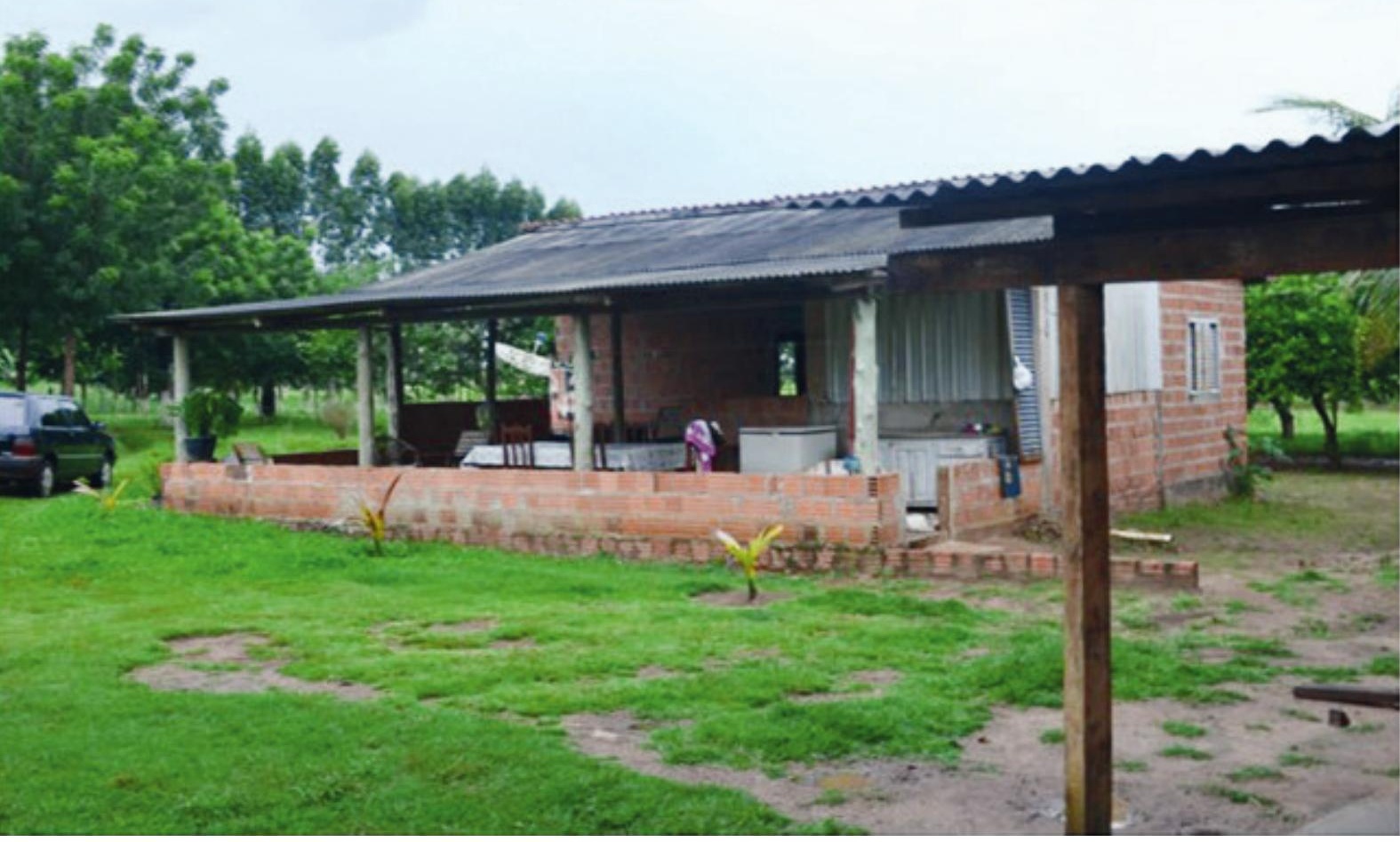

Crédito: Kelly Alves, 2015.

O abastecimento de água para consumo humano provém de poço particular comum ou semiartesiano (mais profundo e necessita de bombeamento para a retirada da água). 70\% dos entrevistados utilizam água natural, 30\% são abastecidos com água do poço coletivo originada na comunidade. Desse total, 60\% afirmaram utilizar o filtro de barro como forma de tratamento, sendo que os demais não usufruem de nenhum tipo de tratamento para a água. Em relação aos aspectos sanitários, todas as propriedades possuem fossa subterrânea, embora alguns demonstrarem interesse em construir fossas sépticas para evitar contaminação do lençol freático, porém não dispondo de condições financeiras para a sua construção.

Quanto ao lixo doméstico, identificou-se que 65\% dos moradores queimam, 15\% enterram, 12,5\% depositam no lixão da cidade e 7,5\% jogam a céu aberto. Muitas vezes a falta de informação ou conhecimento técnico sobre as problemáticas do lixo, bem como a ausência de locais ideais para a coleta e destinação ambientalmente adequada, leva os agricultores à escolha de práticas 
mais simples como depositar o lixo a céu aberto, queimar ou enterrar, como observado por Sousa, Khan e Passos (2002). Tais práticas demonstram que existe pouca ou nenhuma informação em relação ao cuidado com o meio ambiente principalmente no que se refere à saúde da população e à preservação ambiental. A fumaça provocada com a queima do lixo é um meio propicio para que os agentes químicos cheguem às vias respiratórias causando problemas de saúde (REGO; COÊLLHO; BARROS, 2014).

Quando indagados como é realizada a limpeza (retirada de plantas daninhas) na propriedade, $82,5 \%$ dos entrevistados responderam que não queimam nada, $15 \%$ que no início colocaram fogo para limpar a propriedade, mas que atualmente não utilizam mais dessa prática, 2,5\% queimam as folhas do quintal.

No que se refere à queimada, percebeu-se uma sensibilização por parte dos entrevistados, pois a maioria afirmou que é perigosa esta prática, devido ao fogo alastrar-se além da área delimitada, principalmente no período da seca. Afora isso, a fumaça contribui para o aumento da poluição atmosférica e, consequentemente, para os problemas respiratórios da população. Evitar as queimadas é preservar os recursos naturais, como proteger a biota do solo, a fauna, flora, os recursos hídricos e a saúde das pessoas na comunidade.

Todos os entrevistados declararam fazer uso de agrotóxicos, porém quando questionados sobre a utilização de Equipamentos de Proteção Individual (EPI), para o manuseio e o uso dos agrotóxicos, 57,5\% responderam usar máscara, luvas, avental e botas; 30\% usam somente máscaras, pois é isso que possuem, e 12,5\% usam o equipamento completo. Percebeu-se que há falta de conscientização de alguns entrevistados referente à importância da utilização dos EPI, alguns não fazem uso em razão de problemas financeiros para aquisição e outros pelo desconforto que os EPIs proporcionam. Este fato foi também identificado no estudo de Santos, Santos e Dantas (2012), que, além do baixo poder aquisitivo para aquisição dos EPIs, existe ainda a falta de orientação técnica.

Quando questionados se tiveram algum tipo de intoxicação relacionado ao uso dos agrotóxicos, 95\% dos entrevistados responderam que não, e 5\% já foram intoxicados. Rozemberg e Peres (2003) enfatizam que o progresso tecnológico e o incremento dos saberes das ciências humanas e sociais não são suficientes para que se perceba, no meio rural, parcerias entre os agricultores e os técnicos, quando se refere a traçar estratégias que envolvam a produção agropecuária, saúde, educação e segurança no trabalho. 


\subsection{ASPECTOS RELACIONADOS À PRODUÇÃO}

Foi questionado sobre quais alimentos eram produzidos antigamente que proporcionavam a principal renda para a família, uma vez que todo o entrevistado tem origem rural. Observou-se que houve uma mudança nas culturas, alguns dos alimentos produzidos antigamente, como soja, milho e arroz, hodiernamente fazem parte das produções em grande escala. Dados do IBGE (2014) apresentam o arroz, o milho e a soja como os três principais produtos cultivados. Juntos, representam $91,4 \%$ da estimativa da produção e respondem por $85,3 \%$ da área a ser colhida. Atualmente se cultiva mandioca, banana, maracujá e abacaxi; e se criam frangos, sendo estes os mais representativos. Tais produtos, mesmo em pequenas áreas, podem gerar bons retornos e possibilitam a comercialização na própria unidade produtiva.

Quando questionados sobre as dificuldades enfrentadas para a produção de alimentos, não foi possível delimitar quais eram os problemas específicos, pois alguns entrevistados responderam mais de uma dificuldade, tais como: 100\% afirmaram falta de recursos financeiros, 87,5\% falta de água, 75\% falta de assistência técnica e 37,5\% dificuldade de escoar a produção.

Em relação à atividade que gostariam de desenvolver na propriedade, $60 \%$ afirmaram ter interesse em produzir frutas e hortaliças, e o restante distribuídos em outras atividades (Tabela 1 ).

Tabela 1 - Atividades que os agricultores da Comunidade Vale do Sol II gostariam de desenvolver na propriedade que ainda não conseguiram

\begin{tabular}{l|c}
\hline Resposta & Quantidade \\
\hline Frutíferas & $32,5 \%$ \\
\hline Hortaliças & $27,5 \%$ \\
\hline Melhorar a estrutura para criação de frangos & $25 \%$ \\
\hline Farinheira & $10 \%$ \\
\hline Estufa para produção de mudas & $5 \%$ \\
\hline Total & $\mathbf{1 0 0} \%$ \\
\hline
\end{tabular}

Sobre a origem da principal renda, 25\% dos agricultores responderam que decorre da produção de mandioca, 22,5\% venda de frango, 15\% venda de abacaxi, 12,5\% produção de banana, 10\% aposentadoria e o restante de atividades diversas, como: venda de polpa de maracujá, hortaliça, feira do produtor, tratorista e aluguel de imóvel. 
Identificou-se que culturas como a mandioca, o abacaxi e a banana poderiam ser manuseadas de forma a agregar valor, pois a mandioca que é vendida no local de origem, se industrializada poderia transformar-se em farinha, polvilho ou outros, bem como o abacaxi e a banana em doces ou polpas de frutas. No entanto, para que isto ocorra, mudanças significativas são necessárias, por exemplo: organização social dos interessados, interesse político e aperfeiçoamento na cadeia produtiva.

\subsection{ASPECTOS RELACIONADO À EDUCAÇÃO E SAÚDE}

Foi verificado in loco que não há estrutura física de escola na comunidade, no entanto os alunos se deslocam até as unidades escolares do município, pois a Prefeitura Municipal de Tangará da Serra disponibiliza ônibus escolar para transportar as crianças e adolescentes da comunidade até as escolas. Diariamente o ônibus leva as crianças no período matutino até a escola do distrito de Progresso e no período vespertino para escolas na cidade de Tangará da Serra.

Segundo as mães, a grande dificuldade para as crianças é acordar cedo todos os dias para pegar o ônibus. Uma mãe relatou que seu filho tem 4 anos e ainda não vai para escola, pois o transporte só carrega a partir de 5 anos. Porém, o Estatuto da Criança e Adolescente (ECA) em seu artigo 54, inciso IV, expressa que é dever do Estado assegurar a criança de 0 a 06 anos de idade atendimento a creche e pré-escola. Nesse aspecto o poder público municipal alega que oferta o estudo, porém não é dever do mesmo o transporte para crianças abaixo de 5 anos. Em relação ao ensino de jovens e adultos e/ou cursos de aperfeiçoamento, os entrevistados relataram que são poucos os cursos ofertados.

Na contramão desta realidade, Souza-Esquerdo et al. (2013) descrevem que a localização da escola dentro do assentamento ou comunidade rural é fundamental, pois é um espaço de socialização e integração das novas gerações, bem como a integração social das famílias.

Quanto ao acesso à saúde, a comunidade não possui Unidade de Estratégia de Saúde da Família. No entanto, em dezembro de 2014, iniciaramse atendimentos às sextas-feiras, por uma médica e uma enfermeira vindas de Tangará da Serra. Estes atendimentos ocorrem na sede da comunidade e são realizadas consultas, prescrição de exames laboratoriais, de imagens e medicamentos, encaminhamentos aos serviços de referência e contra referência 
aos serviços especializados, de apoio diagnóstico e terapêutico, ambulatorial e hospitalar. Porém, não há insumos básicos como: materiais para curativos, soros, gaze, equipos, medicamentos, vacinas, soluções, dentre outros.

Os indicadores de qualidade de vida estão relacionados a saúde, à boa alimentação e ao viver bem, uma vez que a saúde possibilita o emaranhar-se no tecido socioeconômico da população, sendo ela fator imprescindível na geração de renda, trabalho, lazer, educação etc.; condicionantes essenciais para que se desfrute de bem-estar.

Quando questionados sobre o que é qualidade de vida, surgiu mais de uma opção para cada resposta, pois se tratou de pergunta aberta. A resposta saúde e educação prevaleceram, com 75\% das menções, seguida por assistência técnica, vida no campo e alimentação diversificada, com 40\%, 37,5\% e 32,5\%, respectivamente.

A assistência técnica que contribua com o sistema produtivo teve grande predominância entre os entrevistados da Comunidade Vale do Sol II, pois acreditam que tendo acesso a assistência técnica poderiam melhorar a produção em quantidade, qualidade e diversidade, e, dessa forma, obter melhores resultados econômicos, impactando na melhoria da qualidade de vida.

Houve também a indicação de necessidades específicas e concretas, tais como: conforto na moradia, linha de transporte para acesso à cidade e estradas adequadas; reivindicações todas mencionadas pelos entrevistados. Dessa forma, percebe-se que o poder público, através de programas e medidas governamentais, poderia interferir na melhoria da qualidade de vida da comunidade.

\section{CONSIDERAÇÕES FINAIS}

Para os moradores da comunidade Vale do Sol II, a qualidade de vida está relacionada a indicadores como: moradia, alimentação adequada, saúde, educação e relações sociais. Verificou-se que há uma produção maior de mandioca, banana, maracujá, abacaxi e a criação de frango; produtos esses que são a base da economia das famílias e contribuem com a alimentação e a qualidade de vida. Mostraram-se interessados principalmente em diversificar a produção de alimentos, investindo na produção de outras espécies de frutíferas e hortaliças, contribuindo para o aumento da renda e melhores condições de vida. Diversificar a produção de alimentos é contribuir com a conservação ambiental. 
No entanto, os entrevistados relataram problemas que dificultam a vida no campo, como falta de recursos econômicos e assistência técnica qualificada, água para aumentar e diversificar a produção e dificuldade de acesso ao centro da cidade para escoar a produção, bem como a inexistência de transporte coletivo para a cidade. Tais problemas, se solucionados, poderiam auxiliar para manter o homem no campo, garantindo-lhes renda, contribuindo com qualidade de vida da população, bem como abastecer o comércio local com produtos de maior qualidade.

Considera-se, assim, que a sustentabilidade da agricultura familiar está diretamente relacionada aos processos de transformação dos meios de produção, da mudança nos sistemas produtivos, do manejo do sistema agrário, das políticas públicas, da participação dos atores envolvidos, desde o agricultor até o consumidor e das entidades organizacionais e representativas dos agricultores, comprometidas com o crescimento e o desenvolvimento da agricultura familiar.

\section{REFERÊNCIAS}

AZEVEDO, E. Qualidade de vida na perspectiva da agricultura familiar orgânica. In: ENCONTRO NACIONAL DA ANPPAAS, 4., Brasília, 2008. Anais [...]. Brasília, 2008. p. 1-19.

BARROZO, L. C. R. et al. Projeto de assentamento e qualidade de vida dos produtores rurais: o caso do assentamento Santa Barbara II no Ceará. In: CONGRESSO DA SOCIEDADE BRASILEIRA DE ECONOMIA, ADMINISTRAÇÃO E SOCIOLOGIA RURAL, SOBER, 48., Campo Grande, 2010. Anais [...]. Campo Grande, 2010. p. 1-21.

BRASIL. Ministério da Saúde. Conselho Nacional da Saúde. $8^{\mathbf{a}}$ Conferência Nacional de Saúde. Relatório final. Brasília: Ministério da Saúde, 1986.

BRASIL. Ministério do Desenvolvimento Social. Agricultura Familiar, 2014. Disponível em: http://www.brasil.gov.br/centrais-de-conteudo/imagens/mds/ agricultura-familiar. Acesso em: 20 mai. 2015.

BRASIL. Lei Federal n ${ }^{\mathbf{0}}$ 11.326, de 24 de julho de 2006. Estabelece as diretrizes para a formulação da Política Nacional da Agricultura Familiar e Empreendimentos Familiares Rurais. 2006. Disponível em: http://www.planalto.gov.br/ccivil_03/_ Ato2004-2006/2006/Lei/L11326.htm. Acesso em: 24 maio 2015. 
BUSS, P. M. Promoção da saúde e qualidade de vida. Ciência \& Saúde Coletiva, Manguinhos, v. 5, n. 1, p.163-177, 2000.

CASTRO, D. F. V.; FRACOLLI, L. A. Qualidade de vida e promoção da saúde: em foco as gestantes. O Mundo da Saúde, São Paulo, v. 37, n. 2, p.159-165, 2013. COMPANHIA NACIONAL DE ABASTECIMENTO. Agricultura familiar, 2013. Disponível em: http://www.conab.gov.br. Acesso em: 27 abr. 2015.

DENARDI, R. A. Agricultura familiar e políticas públicas: alguns dilemas e desafios para o desenvolvimento rural sustentável. Agroecologia e desenvolvimento rural sustentável, Porto Alegre, v.2, n. 3, p. 56-62, jul./set. 2001.

GIL, A. C. Como elaborar projetos de pesquisa. 4. ed. São Paulo: Atlas, 2007. GOUVEIA, C. N. N. A. Avaliação do impacto do Programa Nacional de Fortalecimento da Agricultura Familiar (PRONAF), na qualidade de vida de jovens agricultores familiares paraibanos. 2010. 208f. Dissertação (Mestrado em Psicologia Social) - Programa de Pós-Graduação em Psicologia, Universidade Federal da Paraíba, João Pessoa, 2010.

GUANZIROLI, E. C. Perfil da agricultura familiar no Brasil: dossiê estatístico. Brasília: FAO/INCRA,1996.

HEBERLÊE, A. L. O. Agricultura familiar no contexto mundial. Brasília, 2014. Disponível em: https://www.embrapa.br/busca-de-noticias/-/ noticia/1871776/artigo-a-agricultura-familiar-brasileira-no-contexto-mundial. Acesso em: 08 maio 2015.

IBGE. Censo agropecuário 2006 agricultura familiar. Rio de Janeiro, 2006. Disponível em: http.www.ibge.gov.br. Acesso em: 12 maio 2015.

IBGE. Sistema IBGE de recuperação automática (SIDRA). Rio de Janeiro, 2010. Disponível em: http://www.sidra.ibge.gov.br/. Acesso em: 28 abr. 2015.

IBGE. Produção Agrícola 2014. Rio de Janeiro, 2014. Disponível em: http.www. ibge.gov.br/Producao_Agricola/Levantamento_Sistematico_da_Producao_ Agricol. Acesso em: 29 jan. 2016.

MALHOTRA, N. K. Introdução a pesquisa de marketing. São Paulo: Prentice Hall, 2012. 
MARCONI, M. A.; LAKATOS, E. M. Fundamentos de metodologia científica. São Paulo: Atlas, 2007.

MATHEUS, M. C. C; FUSTINONI, S. M. Pesquisa qualitativa em enfermagem. São Paulo: Livraria Médica Paulista, 2006.

MINAYO, M. C. S. Pesquisa social: teoria, método e criatividade. Rio de Janeiro: Vozes, 2004.

MINISTÉRIO DO DESENVOLVIMENTO AGRÁRIO. Plano safra da agricultura familiar 2014/2015. Brasília: MDA, 2015. Disponível em: http:// www.mda.gov.br. Acesso em: 14 maio 2015.

OLIVEIRA, R. K. P. et al. Agricultura familiar em assentamentos rurais no município de Cáceres/MT: uma leitura socioeconômica. In: CONGRESSO BRASILEIRO DE AGROECOLOGIA, 8., Porto Alegre, 2013. Resumos [...]. Porto Alegre, 2013.

PIGOU, A.C. The Economics of Welfare. Macmillan, London, 1920.

REGO, F. A. H.; COÊLLHO, J. R.; BARROS, V. L. L. Análise dos efeitos negativos causados pela queima do lixo doméstico em áreas urbanas de Caxias (MA). Revista Humana Et Al, Paço do Lumiar, v. 1, n. 1, p. 50-60, jul. 2014.

ROBLE, G. L. E. Qualidade de vida no trabalho: um estudo em empresas que publicam balanço GRI. 2012. 118f. Dissertação (Mestrado em Administração) Programa de Estudos Pós-Graduados em Administração, Pontifícia Universidade Católica de São Paulo, São Paulo, 2012.

ROZEMBERG, B.; PERES, F. Reflexões sobre a educação relacionada aos agrotóxicos em comunidades rurais. Rio de Janeiro: Fiocruz, 2003.

SANGALLI, A. R; SCHLINDWEIN, M. M. A contribuição da agricultura familiar para o desenvolvimento rural de Mato Grosso do Sul - Brasil. Revista de Desenvolvimento Regional, Blumenau, v. 18, n. 3, p. 82-99, set./dez. 2013. SANTOS, M. E. O.; SANTOS, H. C.; DANTAS, H. J. O uso indiscriminado de agrotóxico na agricultura familiar no assentamento Aroeira no município de Santa Terezinha-PB. In: CONGRESSO NORTE NORDESTE DE PESQUISA E INOVAÇÃO, 7., Palmas, 2012. Anais [...]. Palmas, 2012. p. 1-8.

SILVA, E. R. A. Programa Nacional de Fortalecimento da Agricultura Familiar - Pronaf: uma avaliação das ações realizadas no período 1995/1998. 
Brasília: MDA, 2000. Disponível em: http://www.gipaf.cnptia.embrapa.br. Acesso em: 12 maio 2015.

SIQUEIRA, D. F. Qualidade de vida de trabalhadores rurais de comunidades assistidas pelo Instituto Agronômico de Pernambuco (IPA) no município de Santo Antão-PE. 2011. 135f. Dissertação (Mestrado em Saúde Humana e Meio Ambiente) - Programa de Pós-Graduação em Saúde Humana e Meio Ambiente, Universidade Federal de Pernambuco, Vitória de Santo Antão, 2011.

SOCIEDADE NACIONAL DA AGRICULTURA. Secretário da Agricultura em MT terá olhos voltados para pequeno produtor. Rio de Janeiro: SNA, 2015. Disponível em: http://www.sna.agr.br. Acesso em: 16 maio 2015.

SOUSA, M. C.; KHAN, A. S.; PASSOS, A. T. B. Qualidade de vida da agricultura familiar em assentamentos de reforma agrária do Rio Grande do Norte. 2002.

SOUZA, C. Políticas públicas: uma revisão da literatura. Sociologias, Porto Alegre, v. 8, n. 16, p. 20-45, jul./dez. 2006.

SOUZA-ESQUERDO, V. F. et al. Segurança alimentar e nutricional e qualidade de vida em assentamentos rurais. Segurança Alimentar e Nutricional, Campinas, v. 20, n. 1, p. 13-23, 2013.

TREVISSAN, S. P. Ciência, meio ambiente e qualidade de vida: uma proposta de pesquisa para uma universidade comprometida com sua comunidade. Ciência e Saúde Coletiva, Manguinhos, v. 5, n. 1, p. 170-186, 2000.

VERGARA, S. C. Projetos e relatórios de pesquisa em Administração. São Paulo: Atlas, 2007. 